\title{
Recanalization and reperfusion therapies of acute ischemic stroke: what have we learned, what are the major research questions, and where are we headed?
}

\section{Meritxell Gomis * and Antoni Dávalos}

Stroke Unit, Neurosciences Department, Hospital Universitari Germans Trias i Pujol, Badalona, Spain

\section{Edited by:}

Svetlana Lorenzano, Sapienza

University of Rome, Italy

Reviewed by:

Alejandro Rabinstein, Mayo Clinic, USA

Edward Feldmann, Brown University, USA

\section{${ }^{*}$ Correspondence:}

Meritxell Gomis, Stroke Unit, Neurosciences Department, Hospital Universitari Germans Trias i Pujol, Carretera de Canyet $s / n$, Badalona 08916, Spain

e-mail:meritxellgomis@gmail.com
Two placebo-controlled trials have shown that early administration of intravenous recombinant tissue plasminogen activator (rt-PA) after ischemic stroke improves outcomes up to $4.5 \mathrm{~h}$ after symptoms onset; however, six other trials contradict these results. We also know from analysis of the pooled data that benefits from treatment decrease as time from stroke onset to start of treatment increases. In addition to time, another important factor is patient selection through multimodal imaging, combining data from artery status, and salvageable tissue measures. Nonetheless, at the present time randomized controlled trials (RCTs) cannot demonstrate any beneficial outcomes for neuroimaging mismatch selection after $4.5 \mathrm{~h}$ from symptoms onset. By focusing on cases of large arterial occlusion, we know that recanalization is crucial, so endovascular treatment is an approach of interest. The use of intra-arterial thrombolysis was tested in two small RCTs that demonstrated clear benefits in terms of higher recanalization and also in clinical outcomes. But a new paradigm of stroke treatment may have begun with mechanical thrombectomy. In this field, Merci devices have been overtaken by fully deployed closed-cell self-expanding stents (stent-retrievers or "stent-trievers"). However, despite the high rate of recanalization achieved with stentretrievers compared with other recanalization treatments, the use of these devices cannot clearly demonstrate better outcomes. Thus, futile recanalization occurs when successful recanalization fails to improve functional outcome. Recently, three RCTs, namely synthesis, IMS-III, and MR-rescue, have not been demonstrated any clear benefit for endovascular treatment. Most likely, these trials were not adequately designed to prove the superiority of endovascular treatment because they did not use optimal target populations, vascular status was not evaluated in all patients, relatively high rates of patients did not have enough mismatch, time from baseline neuroimaging to recanalization were too long or the devices used are now obsolete relative to stent-retrievers. Several RCTs currently underway are trying to determine whether bridging therapy is more effective than intravenous treatment and if mechanical thrombectomy is more effective than best medical treatment in patients ineligible for intravenous thrombolysis.

Keywords: mechanical thrombectomy, ischemic stroke, stent-retriever, endovascular clinical trials, futile recanalization, reperfusion

\section{INTRODUCTION}

Intravenous recombinant tissue plasminogen activator (rt-PA) is the only approved treatment for acute ischemic stroke within $4.5 \mathrm{~h}$ from symptoms onset, as supported by two placebo-controlled trials $(1,2)$, meta-analyses $(3-5)$, and observational studies $(6,7)$. However, many patients are still left undertreated due to the fact of factors such as an unknown onset time for the stroke, the narrow time window, a lack of awareness that stroke has occurred or the high number of exclusion criteria for currently approved treatments.

Several strategies have been developed in order to increase the number of treated patients. The EPITHET and DEFUSE studies suggest that multimodal neuroimaging may help to select patients with salvegeable brain tissue up to $6 \mathrm{~h}$ after stroke onset $(8,9)$.
EPITHET was a prospective, randomized, double blind, placebocontolled, and phase II trial that tested alteplase between 3 and $6 \mathrm{~h}$ after stroke onset in patients who were imaged with serial echoplanar MRI at baseline and at $3-5$ days after therapy. The primary outcome measure was attenuation of infarct growth. Although there was a non-significant trend toward a positive result, in the subgroup of patients with mismatch alteplase was significantly associated with increased reperfusion and improved clinical outcomes (8). The method of measuring this mismatch volume was the standard volumetric technique in which volumes were calculated by simple subtraction. A more precise method based on coregistration of DWI and PWI images showed larger mismatch volumes and significant attenuation of infarct growth by alteplase (9). DEFUSE, an open-label study of intravenous alteplase from 
3 to $6 \mathrm{~h}$ from stroke onset, showed that the occurrence of early reperfusion led to good clinical outcomes in patients with target mismatch. This mismatch profile was defined as a PWI lesion that was $10 \mathrm{ml}$ or more and $120 \%$ or more of the DWI lesion. DEFUSE also identified an MRI pattern called "malignant profile," characterized by a DWI lesion $100 \mathrm{ml}$ or more and/or a large PWI lesion of $100 \mathrm{ml}$ or more with $8 \mathrm{~s}$ or longer of $\mathrm{T} \max$ delay. The target profile appears to identify patients with an especially robust clinical response rate $(67 \%)$ after early reperfusion whereas the malignant profile is strongly associated with reperfusion-related brain hemorrhage.

Besides alteplase, new thrombolytic drugs like tenecteplase and desmoteplase may potentially be safer in extended windows up to 6 or $9 \mathrm{~h}$ from symptoms onset in patients with salvageable brain tissue. Tenecteplase is a third generation point mutation tissue plasminogen activator that has a longer half-life, greater binding affinity for fibrin and better resistance to inactivation by the endogenous inhibitor PAI-1 compared to alteplase. In a nonrandomized study of ischemic stroke patients with $\mathrm{CT}$ perfusion mismatch within 3-6h of symptoms onset, tenecteplase at low dose $(0.1 \mathrm{mg} / \mathrm{kg})$ appeared to be superior to alteplase (10). A posterior randomized phase IIb study using a similar design found that moderate $(0.25 \mathrm{mg} / \mathrm{kg})$ and low doses $(0.1 \mathrm{mg} / \mathrm{kg})$ of tenecteplase yielded significantly better patient outcomes than standard doses of alteplase. Tenecteplase was associated with increased reperfusion, early neurological improvement, and improved 3 month functional outcome with the higher dose without an increase in ICH rate (11).

Desmoteplase is a thrombolytic drug extracted from the saliva of vampire bats. It is more selective for fibrin and has not been to shown to have any deleterious effect on the blood brain barrier compared to alteplase. Two promising phase II studies, DIAS and DEDAS, demonstrated increased reperfusion and strong trends to improved outcome with desmoteplase compared with placebo in acute stroke patients using imaging selection with CT perfusion or multimodal MRI treated within 3-9 h from stroke onset $(12,13)$. These trial results, however, were not confirmed in DIAS-2 (14). The main reasons for this neutral effect might lie in the lack of standardized imaging assessment of penumbra and the substantial number of patients without main cerebral arterial occlusions. A pooled analysis of DIAS, DEDAS, and DIAS-2 results showed that patients with proximal vessel occlusion or high grade stenosis had greater mismatch and positive response to desmoteplase compared to placebo (15). Current ongoing DIAS-3 and DIAS-4 trials were designed to correct the errors of DIAS-2 (16).

A critical point to obtain a favorable risk/benefit effect of extended intravenous thrombolysis is the existence of an arterial occlusion. A post hoc study of pooled data from EPITHET and DEFUSE showed a benefit for intravenous tPA over placebo on infarct growth attenuation only in patients with arterial occlusion (17). Regarding occlusion site, the more distally the occlusion is located, the higher the likelihood of recanalization. By using transcranial Doppler, complete recanalization at $2 \mathrm{~h}$ after intravenous rt-PA bolus has been shown in 44,29 , and $10 \%$ of cases involving distal middle cerebral artery, proximal middle cerebral artery, and terminal internal carotid artery, respectively (18). However, some adjunctive strategies like sonothrombolysis appear to be safe and obtain higher complete recanalization rates after intravenous thrombolysis. The CLOTBUST-HF study (19) included 20 patients, with 14 of the $20(70 \%)$ occlusions occurring in the middle cerebral artery (12 of these 14 in the proximal middle crebral artery), 3 more (15\%) in the terminal carotid artery, and the remaining $3(15 \%)$ in the verebral artery. Rates of complete recanalization at $2 \mathrm{~h}$ were 8 out of $20(40 \%)$, all of them MCA occlusions (i.e., 8 or $57 \%$ of the 14 ).

Due to the fact that the effect of tPA is limited in proximal occlusions, other approaches have been tested to open the occluded vessels. Endovascular treatment may be an option to increase recanalization and therefore effective reperfusion rates. A number of trials have tested this hypothesis (Table 1). Endovascular treatment covers two different modalities: intra-arterial administration of thrombolytic drugs, mainly rt-PA and urokinase, and mechanical thrombectomy. Both modalities have the disadvantage over intravenous approaches that they require additional time to be started and are available only in specialized centers. However, the first modality achieves benefits not only because it delivers the drug just into the clot but also from the mechanical effect of the catheter. The PROACT II trial was the first trial to show the benefit of intra-arterial pro-urokinase compared to placebo. Intracranial hemorrhage with neurological deterioration within $24 \mathrm{~h}$ occurred in $10 \%$ of pro-urokinase patients and $2 \%$ of control patients $(p=0.06)$. All symptomatic intracranial hemorrhages occurred in patients with a baseline NIHSS score of 11 or higher (20). Thereafter, the interventional management of stroke (IMS) I and II trials suggested the feasibility and safety of a bridging intra-arterial/intravenous approach compared with intravenous tPA alone. However, the proportion of patients with good clinical outcome (mRS $0-2$ ) at 3 months was only slightly superior in IMS I and II (43 and 46\%) compared with patients treated with intravenous tPA in the NINDS trial (39\%), although the differences were higher compared with the NINDS placebo subgroup $(28 \%)(21,22)$. This treatment modality has since been overtaken by mechanical thrombectomy and in particular by thrombus retrieval.

Mechanical approaches compared to intra-arterial pharmacological therapy are associated with greater technical difficulty, the potential development of vasospasm, vessel dissection, perforation or rupture, and distal embolization into previous unaffected territories due to fragmented thrombus. The MERCI ${ }^{\circledR}$ device achieved complete recanalization in $48 \%$ of acute ischemic stroke patients with large arterial occlusions treated within the first $8 \mathrm{~h}$ from stroke onset (24). The MERCI trial (Table 1) included a large number of patients who were not eligible for intravenous tPA. Their results were comparable with the results of PROACT-II (20) and IMS-II (23). Conversely, mortality was higher in the MERCI trial in accordance with the differences between populations. Arterial recanalization was independently associated with good outcome ( $\mathrm{mRS} \leq 2$ at 3 months), while the absence of recanalization was associated with mortality. Although the recanalization rate with mechanical thrombectomy was similar to that for intra-arterial thrombolysis, only $25 \%$ of MERCI patients achieved a good functional outcome. In the Multi MERCI trial (25) (Table 1), investigators used a new generation of MERCI ${ }^{\circledR}$ devices (L5 Retriever) in patients with large-vessel stroke within $8 \mathrm{~h}$ of symptoms onset. Regarding 
Table 1 | Baseline stroke severity and outcome variables in the main reperfusion trials carried out before the development of stent-retrievers.

\begin{tabular}{|c|c|c|c|c|c|c|}
\hline & $n$ & $\begin{array}{l}\text { Baseline } \\
\text { NIHSS }\end{array}$ & $\begin{array}{l}\text { Successful } \\
\text { recanalization (\%) } \\
\text { (TIMI 2-3) }\end{array}$ & $\begin{array}{l}\text { mRS 0-2 at } \\
90 \text { days }(\%)\end{array}$ & $\begin{array}{l}\text { 90-day } \\
\text { mortality (\%) }\end{array}$ & sICH (\%) \\
\hline \multicolumn{7}{|l|}{ Intravenous thrombolysis } \\
\hline $\begin{array}{l}\text { Pooling analysis of phase IV trials within } 6 \mathrm{~h} \\
\text { (tPA groups) (4) }\end{array}$ & 1391 & 11 & NA & 49 & 13 & $5-9^{b}$ \\
\hline $\begin{array}{l}\text { Pooling analysis of phase IV trials within } 6 \mathrm{~h} \\
\text { including IST-3 (tPA groups) (5) }\end{array}$ & 3548 & - & NA & 46 & 19 & $7^{\mathrm{b}}$ \\
\hline \multicolumn{7}{|l|}{ Endovascular treatment } \\
\hline PROACT II (20) & 121 & 17 & 66 & 40 & 25 & 10 \\
\hline IMS (21) & 62 & 18 & 56 & 43 & 16 & 6 \\
\hline IMS-II (23) & 55 & 19 & 58 & 46 & 16 & 10 \\
\hline MERCI (24) & 141 & 20 & $48^{\mathrm{a}} / 60$ & 28 & 44 & 8 \\
\hline Multi MERCI (25) & 164 & 19 & $55^{a} / 68$ & 36 & 34 & 10 \\
\hline Penumbra (26) & 125 & 18 & 82 & 25 & 33 & 11 \\
\hline \multicolumn{7}{|l|}{ Control groups } \\
\hline $\begin{array}{l}\text { Pooling analysis of phase IV trials within } 6 \mathrm{~h} \\
\text { (placebo groups) }\end{array}$ & 1384 & 11 & NA & 44 & 15 & $1.1^{\mathrm{a}}$ \\
\hline PROACT-II (control group) & 59 & 17 & 18 & 25 & 27 & 2 \\
\hline
\end{tabular}

${ }^{a}$ Device alone.

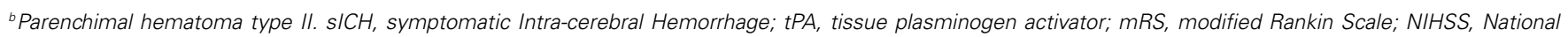
Institutes of Health Stroke Scale.

safety, no differences were seen in the rates of intracranial hemorrhage or clinically significant procedural complications between those patients treated with intravenous IPA and those who were not. Another single-center study obtained similar findings (27). A new thrombectomy system was used in the Penumbra Trial, designed to evaluate the safety and effectiveness of the Penumbra thrombo-aspiration device (26) (Table 1) in patients with acute ischemic stroke within the $8 \mathrm{~h}$ from symptoms onset with NIHSS $\geq 8$ and angiograhic occlusion. Procedural events occurred in $12.8 \%$ of cases, with $2.4 \%$ considered serious. In this study, $25 \%$ of patients achieved a modified Rankin Scale score of $\leq 2$. Taken together, these findings suggest that the Penumbra System obtains higher revascularization rates than those reported for the MERCI ${ }^{\circledR}$ device. The safety profile of the Penumbra System is also favorable but despite this, considering the high revascularization rate, the clinical functional outcome was lower than expected. The absence of imaging-guided patient selection and historical control design in these studies may render elusive a definitive conclusion on longterm outcome. Therefore, the effect of revascularization on clinical functional outcome should only be evaluated by a controlled trial in well-selected patients.

Recently, a new paradigm of more promising stroke treatment has begun with the use of fully deployed closed-cell-expanding stents (stent-retrievers or "stent-trievers"), which achieve recanalization rates of up to $90 \%$. However, improvement of revascularization has not been paralleled by favorable responses in clinical outcome. DEFUSE 2 (28) results for which have only been published recently, was a prospective cohort study that enrolled patients to have endovascular treatment within $12 \mathrm{~h}$ from symptoms onset to establish whether the patient had an MRI baseline profile (target mismatch) predictive of salvageable tissue. A total of 46 out of $78(59 \%)$ patients with target mismatch and 12 out of $21(57 \%)$ patients without target mismatch had reperfusion after endovascular treatment. The adjusted odds ratio (OR) for favorable clinical response associated with reperfusion was 8.8 [95\% confidence interval (CI) 2.7-29.0] in the target mismatch group and $0.2(0.0-1.6)$ in the no target mismatch group ( $p=0.003$ for difference between ORs). Reperfusion was associated with increased good functional outcome at 90 days (OR 4.0; 95\% CI 1.3-12.2) in the target mismatch group, but not in the no target mismatch group (1.9; 0.2-18.7). Thus, this trial showed that target mismatch patients who had early reperfusion after endovascular treatment had more favorable clinical outcomes. No association between reperfusion and favorable outcomes was present in patients without target mismatch.

In the overview that follows, we will analyze the limitations of previous research and discuss future trial designs and as well as the prospects for endovascular treatment for acute ischemic stroke patients.

\section{ENDOVASCULAR TREATMENT FOR ACUTE ISCHEMIC STROKE \\ WHAT HAVE WE LEARNED?}

Recanalization continues to be one of the most powerful predictors of successful outcome and is used as a surrogate of efficacy in acute stroke RCTs. In a formal meta-analysis (29) involving a total of 2066 patients, reported recanalization rates categorized according to the received intervention were spontaneous in $24.1 \%$ of cases, $46.2 \%$ after intravenous thrombolysis, $63.2 \%$ after intra-arterial thrombolysis, $67.5 \%$ after combined intravenous-intra-arterial, and $83.6 \%$ after mechanical thrombectomy. Clinical outcome categorized by as either success or failure in achieving recanalization 
was available from 998 patients. Good functional outcomes at 3 months were more frequent in recanalized vs. non-recanalized patients with OR of 4.43 (95\% CI 3.32-5.91). Three-month mortality was reduced in recanalized patients (OR $0.24 ; 95 \%$ CI $0.16-0.35)$. Rates of symptomatic hemorrhagic transformation did not differ between the two groups (OR 1.11; 95\% CI 0.711.74). These findings thus suggest that recanalization is an appropriate biomarker of therapeutic activity in early phase trials of revascularization therapies in acute ischemic stroke.

Although arterial recanalization and subsequent reperfusion should allow the restoration of brain function when it is done early after ischemic stroke, this often fails. This futile recanalization has been related to multiple downstream embolization, the nonreflow phenomenon caused by blockage of microcirculation or fast recruitment of ischemic tissue into infarction before recanalization. Furthermore, reperfusion can be deleterious, through brain-blood barrier disruption resulting in massive brain edema or hemorrhagic transformation (30). Specifically, Hussein et al. (31) in a multicentre study observed futile recanalization in $49 \%$ of patients who received endovascular treatment for acute ischemic stroke. Age $>70$ years (OR 4.4; 95\% CI 1.9-10.5) and initial NIHSS from 10 to 19 (OR 3.8; 95\% CI $1.7-8.4 ; p<0.001$ ) emerged as independent predictors of futile recanalization.

\section{STENT-RETRIEVERS}

As noted above, removable cerebral stents and clot retriever devices referred to as stent-retrievers are a promising strategy to reinforce mechanical thrombectomy. These devices achieve high rates of recanalization and avoid the hemorrhagic complications associated with the use of antithrombotic drugs needed when an angioplasty and permanent stenting is used to achieve arterial recanalization $(32)$.

\section{Retrospective non-controlled non-randomized studies}

The first reported cases dealt with permanent placement of opencell self-expanding stents to recanalize embolic intracranial artery occlusions by compressing the occluding thrombus represented a big step forward in mechanical thrombectomy $(33,34)$. Multiple small case series reporting the results of the use of stenttrievers have been published. Most of them showed high rates of recanalization and outcome rates comparable with those reported in intravenous thrombolysis trials. In general, patients treated with these devices had higher NIHSS and were treated later than patients treated with intravenous thrombolysis (35-57) (Table 2).

\section{Prospective controlled studies}

The solitaire flow restoration thrombectomy for acute revascularization (STAR) was a prospective, multicentre, single-arm study of mechanical thrombectomy using the Solitaire device (58) that included 202 patients with a median basal NIHSS score of 17 . Successful recanalization was achieved in $79.2 \%$ of patients and favorable neurological outcome in 57.9\%. Procedure-related complications occurred in $7.4 \%$, intracranial hemorrhagic transformation of some sort occurred in $18.8 \%$, with $1.5 \%$ being symptomatic, and mortality at 3 months occurred in $6.9 \%$. A similar study was conducted with the TREVO stent-retriever. The Trevo ${ }^{\circledR}$ study (59) was a prospective, multicentre, and single-arm study in acute stroke patients in which a total of 60 patients were enrolled. A TICI 2b3 was achieved in $78.3 \%$. At 90 days, $55 \%$ of the patients had a favorable neurological outcome (mRS 0-2) and 20\% had died. Patients with successful recanalization (TICI $2 \mathrm{a}, 2 \mathrm{~b}$, and 3 ) had a $60 \%$ rate of good neurological outcome at day 90 (mRS 0-2), whereas no patient without recanalization had a mRS $90<3$. The overall rate of symptomatic intra-cerebral hemorrhage according to the SITS-MOST criteria was 5\% (3/60) (Table 2).

\section{Prospective randomized controlled studies}

Solitaire ${ }^{\mathrm{TM}} \mathrm{AB} / \mathrm{FR}$ and Trevo ${ }^{\circledR}$ were compared with the standard predicate mechanical thrombectomy device, the Merci Retrieval System, in two controlled randomized trials (SWIFT and TREVO2) to test the potential superiority of stent-retrievers. SWIFT (60) was a randomized, parallel-group, non-inferiority trial that randomly allocated 58 patients to the Solitaire group and 55 patients to the Merci group. The primary endpoint was partial or complete recanalization (thrombolysis in myocardial ischemia, TIMI 2 or 3) without symptomatic intra-cerebral hemorrhage, assessed by an independent CoreLab, which was masked to study assignment. Primary analysis was done by intention to treat. The primary efficacy outcome was achieved more often in the Solitaire group than in the Merci group (61 vs. $24 \%$; difference $37 \%$ [95\% CI 19-53], OR 4.87 [95\% CI 2.14-11.10]; $p$ non-inferiority $<0.0001$, $p$ superiority $=0.0001)$. More patients had 3 months good neurological outcome in the Solitaire group than in the Merci group (58 vs. 33\%; difference $25 \%$ [95\% CI 6-43], OR 2.78 [95\% CI 1.25-6.22]; $p$ non-inferiority $=0.0001, p$ superiority $=0.002$ ). Ninety-day mortality was lower in the Solitaire group ( 17 vs. $38 \%$; difference $-21 \%$ [ $95 \% \mathrm{CI}-39$ to -3 ], OR 0.34 [95\% CI $0.14-0.81]$; $p$ non-inferiority $=0.0001, p$ superiority $=0.02$ ). These findings confirm that Solitaire achieves better angiographic results and clinical outcomes than does the Merci Retrieval System. TREVO 2 trial (61) was an open-label randomized controlled trial that included patients aged from 18 to 85 years with confirmed large-vessel occlusion stroke and NIHSS score from 8 to 29 within $8 \mathrm{~h}$ from symptoms onset. Randomization was stratified by age ( $\leq 68$ vs. $69-85$ ) and NIHSS scores ( $\leq 18$ vs. $19-29$ ). The primary efficacy endpoint was thrombolysis in cerebral infarction (TICI) scores $\geq 2$ assesed by an ummasked CoreLab. The primary safety endpoint was a composite of procedure-related adverse events. Analyses were done by intention to treat. The TREVO 2 trial randomly allocated 88 patients to the Trevo group and 90 patients to the Merci group. Seventy-six patients $(86 \%)$ in the Trevo group and $54(60 \%)$ in the Merci group met the primary endpoint (OR 4.22 ; 95\% CI 1.92-9.69; $p$ superiority $<0.0001)$. Incidence of the primary safety endpoint did not differ between groups [13 (15\%) patients in Trevo group vs. 21 (23\%) in the Merci group; $p=0.1826]$. However, vessel perforations were almost 10 times more common with Merci devices (10\%) than with the Trevo retriever $(1 \% ; p=0.0182)$. Notably, these perforations did not seem to have high clinical relevance, since the rates of symptomatic intracranial hemorrhages and periprocedural mortality were similar in the two groups (Table 2).

A single-center, prospective study on 33 patients showed no significant differences between the Trevo and Solitaire stentretrievers (62). 
Table 2 | Comparision of baseline stroke severity and outcome variables in studies using stent-retrievers.

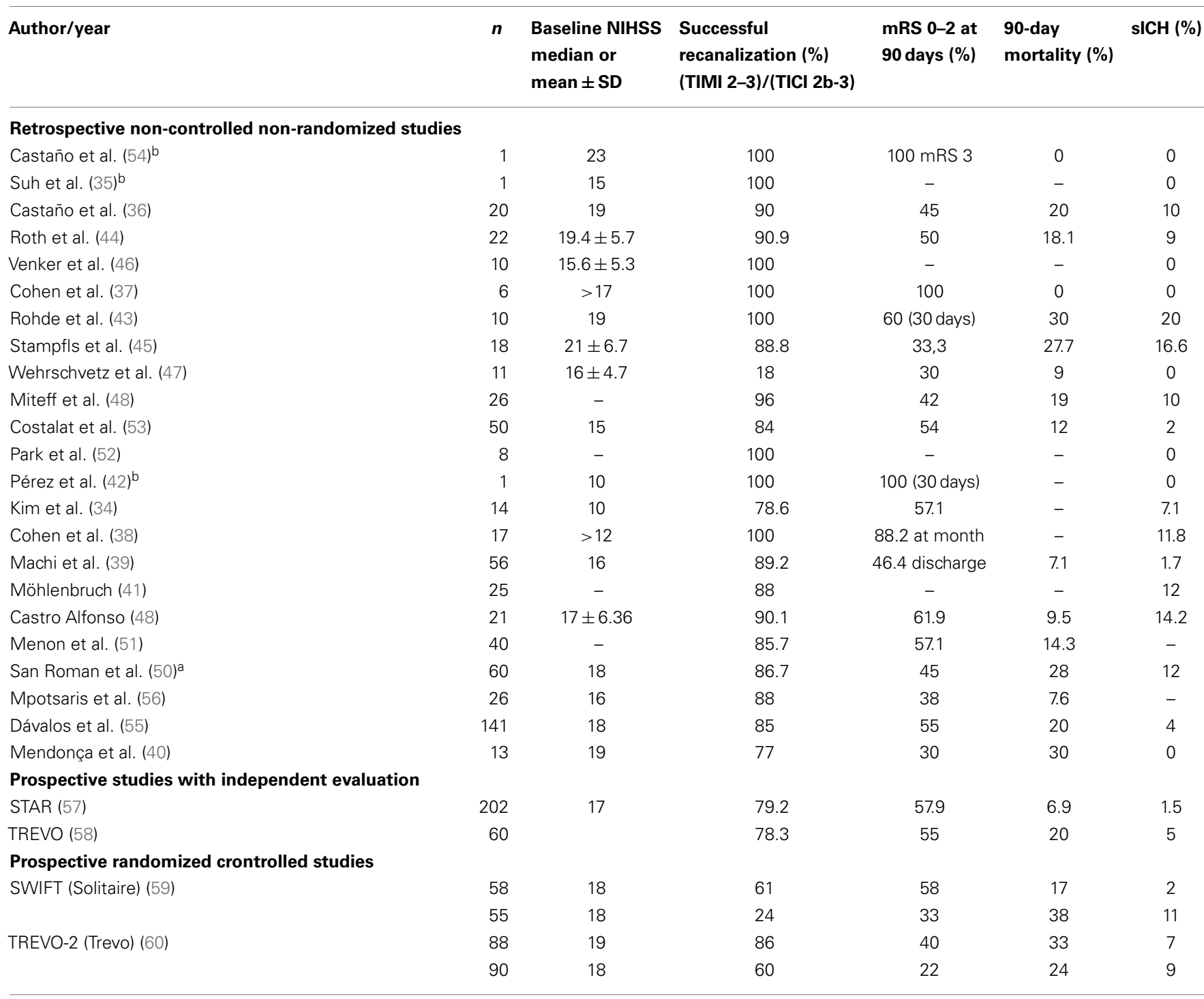

sICH, symptomatic intra-cerebral hemorrhage; mRS, modified Rankin Scale; NIHSS, National Institutes of Health Stroke Scale.

${ }^{a}$ Prospective study.

${ }^{b}$ Single case reports.

The results of these trials were encouraging and support the use of stent-retrievers in prospective trials of endovascular treatment against medical treatment alone.

\section{CONTROLLED TRIALS OF ENDOVASCULAR TREATMENT}

Three randomized clinical trials (IMS-III, SYNTHESIS, and MRRESCUE) (63-65) designed to prove the superiority of endovascular treatment compared to intravenous rt-PA in acute ischemic stroke failed to demonstrate any benefits. We briefly describe the main characteristics and results of these trials, and point out the weaknesses that probably determined the negative results.

The IMS-III (63) was a randomized, parallel-arm trial comparing intravenous tPA followed by endovascular treatment with intravenous tPA alone in patients with acute ischemic stroke within $3 \mathrm{~h}$ from symptoms onset. The angiographic procedure had to begin within $5 \mathrm{~h}$ and be completed within $7 \mathrm{~h}$ after stroke onset. The trial intended to enroll 900 subjects to ensure adequate statistical power to detect an absolute $10 \%$ difference in the percentage of patients with good outcome (mRS 0-2) at 3 months. After 656 patients were randomized (434 participants to endovascular therapy and 222 to intravenous tPA alone), the study was prematurely stopped based on the pre-specified criterion for futility. The proportion of patients with a modified Rankin score of 2 or less at 90 days did not differ significantly according to treatment $(40.8 \%$ with endovascular therapy and $38.7 \%$ with intravenous tPA alone; absolute difference, 1.5 percentage points; $95 \% \mathrm{CI}-6.1$ to 9.1 , after adjustment for the baseline NIHSS score. There were no significant differences between the two treatment arms in the pre-defined subgroups of patients with a NIHSS score $\geq 20$ (6.8 percentage points; $95 \% \mathrm{CI},-4.4$ to 18.1$)$ and $\leq 19$ ( -1.1 percentage point; 
$95 \% \mathrm{CI}-10.8$ to 8.8$)$. Both groups showed similar mortality rates at 90 days ( 19.1 and $21.6 \%$, respectively; $p=0.52$ ) and symptomatic intra-cerebral hemorrhage within $30 \mathrm{~h}$ after initiation of tPA (6.2 and 5.9\%, respectively; $p=0.83$ ).

In the SYNTHESIS trial (64), 362 patients with acute ischemic stroke of less than $4.5 \mathrm{~h}$ after symptoms onset were $1: 1$ randomly allocated to receive intravenous tPA or endovascular therapy (intra-arterial thrombolysis with tPA, mechanical clot disruption or retrieval, or a combinaton of these approaches) within $<6 \mathrm{~h}$ from onset. Primary outcome was survival free of disability at 3 months, defined as modified Rankin score $0-1$. The median time from stroke onset to start of treatment was $3.75 \mathrm{~h}$ for endovascular therapy and $2.75 \mathrm{~h}$ for intravenous $\mathrm{PA}(p<0.001)$. Good primary outcome was found in $30.4 \%$ of patients in the endovascular treatment group and in $34.8 \%$ in the intravenous group (OR adjusted for age, sex, stroke severity, and atrial fibrillation status at baseline $0.71 ; 95 \%$ CI $0.44-1.14 ; p=0.16)$. Symptomatic intracranial hemorrhage within 7 days occurred in $6 \%$ of patients in each group; there were no differences between groups in the rate of other serious adverse events or mortality. Subgroup analysis suggested that the lack of superiority of endovascular therapy was not explained by the time delay to endovascular treatment, stroke subtype, or center. Importantly, the demonstration of vessel occlusion was not a precondition for inclusion in this trial and the use of mechanical thrombectomy devices was limited to Solitaire in 18 patients, Penumbra in 9, Trevo in 5, and Merci in 5.

The MR RESCUE trial (65) was designed to study whether brain imaging could identify patients who were most likely to benefit from therapies for acute ischemic stroke and whether endovascular thrombectomy improved clinical outcome. The trial included patients within $8 \mathrm{~h}$ after the onset of large-vessel, anterior circulation strokes that were randomly assigned to undergo mechanical embolectomy (Merci retriever or Penumbra System) or medical treatment. Randomization was stratified according to whether the patient had a favorable penumbral pattern (substantial salvageable tissue and small infarct core) or a non-penumbral pattern (large core or small or absent penumbra). Among 118 eligible patients, the mean time to enrollment was $5.5 \mathrm{~h}$, and $58 \%$ had a favorable penumbral pattern. Revascularization in the embolectomy group was achieved in $67 \%$ of patients, 90 -day mortality was $21 \%$ and the rate of symptomatic intracranial hemorrhage was $4 \%$; no rate differed across groups. Among all patients, the mean score on the modified Rankin score was equal in the embolectomy and standard of care groups (3.9 vs. 3.9, $p=0.99$ ). Embolectomy was not superior to standard of care in patients with either a favorable penumbral pattern (mean score 3.9 vs. $3.4 ; p=0.23$ ) or a non-penumbral pattern (mean score 4.0 vs $4.4 ; p=0.32$ ). There was no interaction between the pretreatment imaging pattern and treatment assignment on the favorable primary outcome effect $(p=0.14)$. There was a relatively low rate of substantial revascularization in the embolectomy group, which could be related to the use of first-generation embolectomy devices. Long delays up to $5.3 \pm 1.6 \mathrm{~h}$ from imaging to embolectomy and the heterogeneity of imaging approaches based on the use of both MRI and CT were additional factors that might have diluted treatment effect. A favorable penumbral pattern beyond $3 \mathrm{~h}$ may be a signature of more vigorous collateral vessels and therefore of greater tolerance to occlusion, increased likelihood of spontaneous recanalization and good outcome (66). The MR Rescue trial did not show a differential benefit among patients who underwent embolectomy between those with a favorable penumbral pattern as compared with those with a non-penumbral patttern. These findings differ from those in the DEFUSE 2 trial where patients had a shorter time until treatment and smaller predicted infarct cores.

IMS-III and SYNTHESIS did not target the best patient populations to achieve positive results. These trials failed to prove the superiority of endovascular treatment because vascular status was not systematically evaluated, salvageable brain tissue was presumably small or not present in many patients, time from baseline neuroimaging to recanalization was too long and the devices used have been rendered obsolete by stent-retrievers. Despite these limitations, these trials have demonstrated that endovascular treatment is safe and provide data that could be relevant in the design of future trials aiming to prove the applicability of this treatment in certain patients (67-69).

Concerning reperfusion scales, the Thrombolysis in Myocardial Infarction Scale (TIMI), originally constructed to measure myocardial reperfusion, has been widely adopted for use in cerebral circulation (Table 3) (70). The TICI Scale was originally proposed in a position statement that attempted to standardize clinical trial design and reporting for intra-arterial therapy. The TICI scale specifically addresses the extent of tissue reperfusion, as represented by the capillary blush on digital subtraction angiography (71). The original TICI system defined TICI $2 \mathrm{~b}$ as restoration of more than two thirds of the target downstream territory. This is in contrast to the subsequent modified version mTICI (modified treatment in cerebral ischemia introduced by the IMS investigators, which uses a threshold of more than half of the target downstream territory $(22,23)$ (Table 4$)$. In a comparative study of TIMI and mTICI, the c-statistic for predicting 90-day good outcome (mRS 0-2) was significantly higher for mTICI vs. TIMI (0.74 vs. $0.68 ; p<0.0001$ ) (72). Currently, the target angiographic endpoint for assigning technical success should be mTICI $2 \mathrm{~b}$ or higher (73).

In summary, we have learned from these trials that endovascular treatment after tPA is as safe as endovascular treatment alone and that stent-retrievers achieve faster arterial recanalization in

\section{Table 3 |Thrombolysis in Myocardial Ischemia Scale}

\begin{tabular}{ll}
\hline TIMI grades & Definitions \\
\hline Grade 0 & $\begin{array}{l}\text { Absence of any antegrade flow beyond the target occlusion } \\
\text { (no perfusion) }\end{array}$ \\
Grade 1 & $\begin{array}{l}\text { Any faint antegrade flow beyond the target occlusion, with } \\
\text { incomplete filling of the distal branches (penetration withou } \\
\text { perfusion) }\end{array}$ \\
Grade 2 & $\begin{array}{l}\text { Delayed or sluggish antegrade flow with complete filling of } \\
\text { the distal M2 branches flow (partial perfusion) }\end{array}$ \\
Grade 3 & $\begin{array}{l}\text { Normal flow that fills all distal branches, including M3 and } \\
\text { M4 (complete perfusion) }\end{array}$
\end{tabular}

TIMI indicates thrombolysis in myocardial ischemia. 
Table 4 | Modified treatment in Cerebral Ischemia Scale

\begin{tabular}{|c|c|}
\hline mTICI grades & Definitions \\
\hline Grade 0 & No perfusion \\
\hline Grade 1 & $\begin{array}{l}\text { Antegrade reperfusion past the initial occlusion, but } \\
\text { limited distal branch filling with little or slow distal } \\
\text { reperfusion }\end{array}$ \\
\hline Grade 2a & $\begin{array}{l}\text { Antegrade reperfusion of less than half of the occluded } \\
\text { target artery previously ischemic territory (e.g., in one } \\
\text { major division of the MCA and its territory) }\end{array}$ \\
\hline Grade 2b & $\begin{array}{l}\text { Antegrade reperfusion of more than half of the previously } \\
\text { occluded target artery ischemic territory (e.g., in two } \\
\text { major divisions of the MCA and their territories) }\end{array}$ \\
\hline Grade 3 & $\begin{array}{l}\text { Complete antegrade reperfusion of the previously } \\
\text { occluded target artery ischemic territory, with absence of } \\
\text { visualized occlusion in all distal branches }\end{array}$ \\
\hline
\end{tabular}

MCA indicates middle cerebral artery; and $\mathrm{mTICl}$ is modified treatment in cerebral ischemia scale.

acute ischemic stroke. We also have learned that while endovascular therapy may only be useful for selected patients, who we do not yet know how to select optimally, it has not proven useful for stroke patients in general. Thus, it is essential to use the lessons of these trials results in order to design new trials.

\section{HOW CAN WE ADVANCE?}

Randomized controlled trials (RCTs) need to answer a set of open questions. It is very important that they all move together in the same direction and randomize all the eligible patients in order to avoid selection bias. We may make progress through the challenges that a knowledge of previous studies affords us.

\section{Concerning the endovascular treatment arm of the trials}

Recent neutral RCTs of endovascular therapy have shown that the technological improvement of devices moves faster than patient recruitment. Consequently, ongoing and future trials should be inclusive and allow the use of any approved device that interventionalists believe will yield the best results. The main problem with this approach is that different devices or techniques may have different complications and efficacy rates, so merging devices may potentially affect the interpretation of the endovascular arm of the trials.

"Time is brain," so any time delay in treatment administration must be minimized. As in any trial, endovascular stroke trials require mandatory steps that are time-consuming such as obtaining informed consent, checking inclusion, and exclusion criteria and randomization. Therefore, it is important to reduce time delays affecting the endovascular treatment arm through randomization in the angiosuite with team activated, and with a precisely definined standard metric for door-to-groin-puncture time (74). Moreover, these trials might benefit from close cooperation between the different participating centers in order to shorten the delay caused by the transfer of patients.

Centers with best and fastest endovascular stroke treatment facilities should be preferentially considered for such trials, and it is important to carry out extensive preparation and continued education and monitoring of all participating centers to ensure their ability to randomize patients appropriately and achieve as short a time as possible from imaging to reperfusion. Problems generated by this approach are slow recruitment and lack of generalizability of the trial results. Regarding standarization of the procedure, in general, precise metrics need to be defined and monitored. It is also important to have a set of pre-defined actions that should be taken when the center being monitored does not fullfill the required metrics.

There is consensus that, if possible, general anesthesia should be avoided due to the fact that it is associated with worse functional outcome and time delays (75).

\section{Concerning imaging-based patient selection}

There is no doubt that CT or MR imaging including the study of the ischemic core and vessel occlusion is highly recommended for endovascular patient selection. Collateral status has emerged as critical for brain tissue survival until the clot is lysed and sufficient anterograde perfusion is achieved, so an emerging challenge is obtaining additional information about collateral status in endovascular trials (76-79). The Safety and Efficacy of Neuroflo Technology in Ischemic Stroke (SENTIS) trial was the first randomized controlled trial to test the effect of a device to potentially increase collateral blood flow to the brain (80). Although the trial failed to meet the pre-specified primary efficacy endpoint, the safety of the treatment was confirmed. Also, it showed that patients with favorable vascular profiles in multimodal imaging were most likely to benefit from this approach, mainly in the older cohort of patients above 70 years of age (81). Analysis of the IMS III trial results showed that robust angiographic collateral grade was a significant predictor of good clinical outcome at 90 days. Similar findings were seen in the SWIFT and TREVO2 trials. Thus, it appears that collateral evaluation may be used to enhance the approach to treat stroke and to refine future trial designs.

\section{Concerning trial design}

Probably the most important problem for the internal validity of a trial is when a substantial number of eligible patients are presumibily treated outside of the trial. A powerful potential challenge would be to use government-mandated and audited population-based databases of reperfusion therapies (82).

The main outcome based on the degree of functional disability is usually measured by the modified Rankin Score. This score is a monotonic scale, except for the similarity between the two most severe levels, 5 and 6 (83). As a consequence, a "shift" analysis is more likely to find relevant differences in the modified Rankin Score distribution between the two groups in a study than a pre-specified threshold.

\section{Currently, there are two major research questions} Is bridging therapy more effective than intravenous treatment in patients with large-vessel occlusions in the anterior circulation? Bridging therapy is safe but the question about whether it is more effective than intravenous treatment remains open. Trials should compare intravenous thrombolytic treatment as the control group vs. intravenous thrombolysis plus mechanical thrombectomy as 
the experimental group. A trial comparing intravenous tPA vs. mechanical thrombectomy in patients eligible for intravenous thrombolysis could be a reasonable design once combined therapy had been demonstrated to be superior to intravenous tPA.

Bridging therapy might be better than isolated intravenous tPA in patients with proximal vessel occlusions. Trials comparing the two treatment arms should include a baseline imaging vessel study. A rather small proportion of patients in IMS III trial had proximal occlusions. In this subgroup of patients combined treatment was superior to intravenous tPA alone (84).

\section{Is mechanical thrombectomy more effective than best medical} treatment in patients ineligible for intravenous thrombolysis? Trials comparing endovascular treatment vs. best medical treatment without administration of intravenous tPA may be more difficult to carry out since many physicians may consider this design unethical despite the fact that there are no RCTs demonstrating the superiority of endovascular treatment in these situations.

There are several reasons for considering a patient ineligible for intravenous thrombolysis, which can be divided into two different profiles: those that derive from limits in the time window and those that are associated with a higher risk of bleeding such as abnormal hemostasis, anticoagulant treatment with an INR higher than 1.7 or recent (last two months) major surgery. These two groups may have different safety profiles.

Patients arriving for treatment beyond $4.5 \mathrm{~h}$ are ineligible for intravenous rt-PA. Endovascular treatment, mainly mechanical thrombectomy, could be a good alternative treatment but currently there are no results from RCTs answering this open question. In these longer time windows, good clinical outcome is associated with the presence of salvageable brain tissue, which mainly depends on collateral flow status, which in turn may be estimated by means of different imaging modalities, e.g., ASPECTS score, CT angiography source imaging, CT perfusion, or multimodal MRI. A retrospective analysis of one multicentre prospective cohort study (DEFUSE 2) suggested that MRI could diagnose patients who did or did not benefit from the treatment before interventional treatment up to $12 \mathrm{~h}$ from symptom onset. These data need to be confirmed in a randomized study but suggest that the time window for treatment can be extended in some patients. In the Penumbra pivotal stroke trial (27), recanalization benefited patients with a favorable image on the baseline CT scan as indicated by an ASPECTS score $>7$. In fact, some patients are able to maintain a penumbra for as long as $48 \mathrm{~h}(79,85)$ and thus may still benefit from mechanical thrombectomy. Natarajan et al. (86) published a study showing the benefit with safety of endovascular therapy in patients after $8 \mathrm{~h}$ from symptoms onset and wake-up strokes. For these reasons, the use of imaging selection criteria is essential in these studies.

Focusing on the other group of patients, out of the three causes, patients with illness producing abnormal hemostasis are anecdotal. More common are patients undergoing oral anticoagulant treatment, mostly with anti-vitamin $\mathrm{K}$ drugs. In these cases, although only short series are reported in the literature, the results are quite good (87). Patients with recent surgery can not receive endovenous tPA due to the risk of bleeding. These patients can suffer a stroke mediated by a procoagulant state and sometimes favored by the withdrawal of antiplatelets or anticoagulants. Data from several case series have been published showing that the endovascular approach is safe and effective (88).

\section{WHERE ARE WE HEADED?}

Several prospective and randomized clinical trials of mechanical thrombectomy are now enrolling patients to overcome the limitations of previous trials.

The main ongoing randomized clinical trials for mechanical thrombectomy are THRACE, PISTE, MRCLEAN, and REVASCAT in Europe, SWIFT-PRIME in the US, and THERAPY and ESCAPE in Canada (Table 5).

Trial and cost-effectiveness evaluation of intra-arterial thrombectomy in acute ischemic stroke (THRACE) (ClinicalTrials.gov Identifier: NCT01062698) is a multicentre randomized controlled trial with the primary objective of determining whether a combined approach of intravenous thrombolysis (IV) plus mechanical thrombectomy (Merci, Penumbra, Catch, and Solitaire) is superior to IV thrombolysis alone within the $3 \mathrm{~h}$ of onset of symptoms in patients with occlusion of proximal cerebral arteries and a NIHSS $\geq 10$. The secondary aim is to determine the costeffectiveness of this procedure compared to the standard treatment (IV thrombolysis). Projected sample size is 480 patients. At the present time, the recruitment criteria for this study is unknown because the information has not been verified.

Pragmatic Ischemic Stroke Thrombectomy Evaluation [(PISTE); A randomized controlled clinical trial of adjunctive mechanical thrombectomy compared with intravenous thrombolysis in patients with acute ischemic stroke due to an occluded major intracranial vessel] (ClinicalTrials.gov Identifier: NCT01745692) is a randomized controlled trial testing whether mechanical thrombectomy improves functional outcome in patients with large artery occlusion on top of IV thrombolysis. The projected sample size is 800 subjects. This study is not yet open for participant recruitment.

Multicenter Randomized Clinical trial of Endovascular treatment for Acute ischemic stroke in the Netherlands (MR CLEAN) (ISRCTN10888758) is a pragmatic phase III multicentre randomized clinical trial with blinded outcome assessment. The primary objective of this study is to estimate the effect of endovascular treatment on overall functional outcome after acute ischemic stroke of less than 6-h duration in patients with a symptomatic intracranial anterior circulation occlusion. Intervention arm consist of endovascular treatment by means of the local application of rt-PA or urokinase by guided micro-catheter, and/or mechanical thrombectomy, by means of a retraction device, aspiration device, or retrievable stent. The intervention arm could be for patients who have been treated in successfully with IV thrombolysis, patients who can be treated within $6 \mathrm{~h}$ but do not meet the time window requirements for IV thrombolysis, and patients with contraindications for IV or intra-arterial thrombolytic treatment (thrombectomy only). The control arm consists of regular treatment according to current national clinical guidelines, including intravenous t-PA within the first $4.5 \mathrm{~h}$ after symptom onset. The projected sample size is 500 subjects. Recruitment has recently finished. 


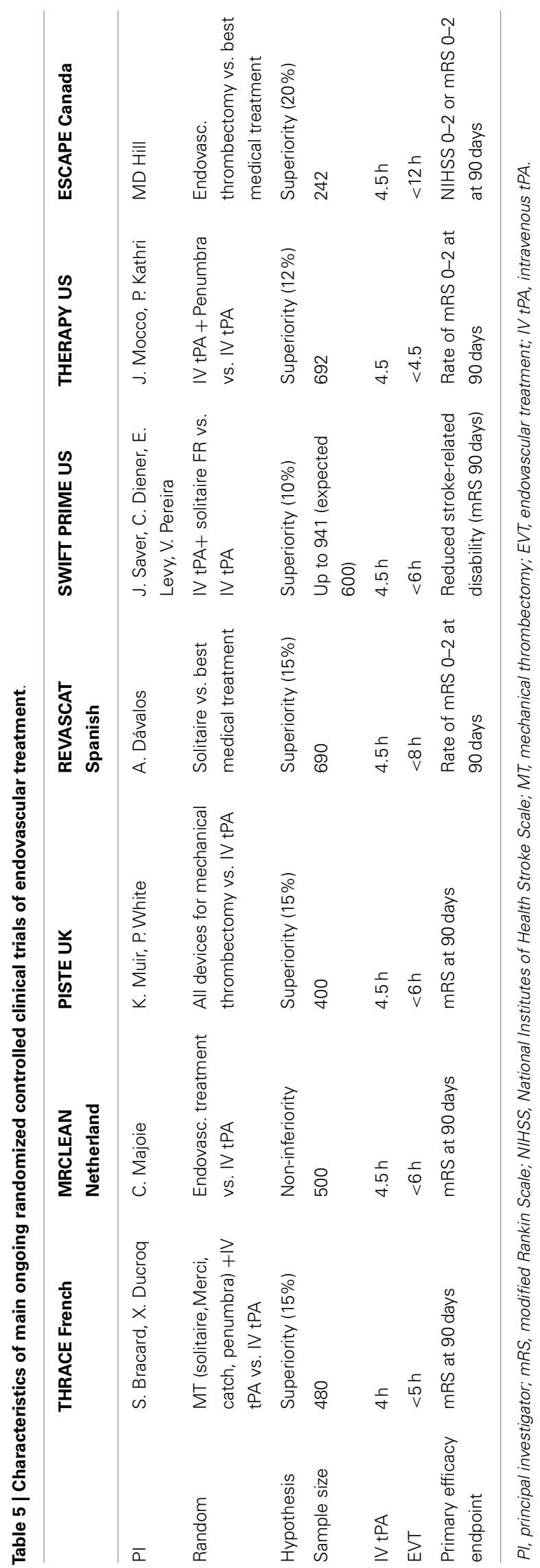

Endovascular Revascularization With Solitaire Device vs. Best Medical Therapy [(REVASCAT) in anterior circulation stroke within $8 \mathrm{~h}$ ] (ClinicalTrials.gov Identifier: NCT01692379) is a prospective, multicentre randomized trial seeking to establish whether subjects meeting the main inclusion criteria of age 18-85, baseline NIHSS $\geq 6$, evidence of TICA or proximal (M1) MCA, ASPECTS score of $\geq 7$ on NCCT or $\geq 6$ on diffusion-weighted MRI, ineligible for or with persistent occlusion after IV alteplase and treated within $8 \mathrm{~h}$ from symptom onset have higher rates of favorable outcome when treated with the Solitaire embolectomy device compared to standard medical therapy alone. The primary endpoint, based on intention-to-treat criteria, is the distribution of mRS scores at 90 days. Maximum sample size is 690 patients with three previous specified interim looks. Randomization is performed under a minimization process using age, baseline NIHSS, therapeutic window, occlusion location, and investigational center. Secondary endpoints are infarct volume evaluated on CT at $24 \mathrm{~h}$, dramatic early favorable response, defined as NIHSS of $0-2$, or NIHSS improvement $\geq 8$ points at $24 \mathrm{~h}$ and successful recanalization in the Solitaire arm according to the TICI classification defined as TICI $2 \mathrm{~b}$ or 3 . Safety variables are mortality at 90 days, symptomatic intracranial hemorrhage rates at $24 \mathrm{~h}$, and procedure-related complications.

Endovascular treatment for small core and proximal occlusion ischemic stroke (ESCAPE) (ClinicalTrials.gov Identifier: NCT01778335) is a phase III, randomized, open-label with blinded outcome evaluation, controlled, parallel-group trial. The primary objectives of this study are to show that rapid endovascular revascularization amongst radiologically selected (small core/proximal occlusion) patients with ischemic stroke results in improved outcome compared to patients treated in clinical routine. Eligible patients will be enrolled within $12 \mathrm{~h}$ of last seen normal with a baseline NIHSS $>5$ at the time of randomization. There must be a confirmed symptomatic intracranial occlusion, based on single phase, multiphase, or dynamic CTA, at one or more of the following locations: carotid T/L, M1 MCA, or M1-MCA equivalent (2 or more M2-MCAs). All patients will receive the best standard of medical care according to modern acute stroke care guidelines (IV alteplase if $<4.5 \mathrm{~h}$ from symptoms onset). Intervention arm consist of endovascular treatment by means of retrievable stent plus other endovascular treatment at discretion of interventionalist. This study consists of one 90-day study period for each subject. This study is in the process of enrolling participants.

Solitaire FR as primary treatment for acute ischemic stroke (SWIFT-PRIME) (ClinicalTrials.gov Identifier: NCT016557461). It is a multicentre, two-arm, prospective, randomized, open, blinded-endpoint study comparing functional outcomes (defined by $\mathrm{mRS}$ ) in acute ischemic stroke patients who are treated with either intravenous tPA alone or intravenous in combination with Solitaire mechanical thrombectomy intervention. The sample size is up to 833 patients. Key inclusion criteria are age $18-85$, prestroke functional independence, NIHSS 8-29, start of intravenous tPA within $4.5 \mathrm{~h}$ of onset, M1 MCA, or intracranial ICA occlusion on CTA or MRA, and target mismatch penumbral profile on multimodal CT or MR imaging. Patients allocated to the device arm will undergo mechanical thrombectomy with up to three passes of the Solitaire stent-retriever. Rapid procedure start is 
emphasized, within 90 min after penumbral imaging. The primary endpoint is degree of global disability at 90 days. Secondary clinical endpoints are all-cause mortality, functional independence (mRS $0-2$ ) at 90 days, and early neurologic deficit improvement (NIHSS change at $24 \mathrm{~h}$ ); secondary technical efficacy endpoints include revascularization/reperfusion at $24 \mathrm{~h}$ and infarct volume at $24 \mathrm{~h}$.

THERAPY trial (A Prospective, Randomized Trial to Assess the Role of Mechanical Thrombectomy as Adjunctive Treatment to IV rtPA) (ClinicalTrials.gov Identifier: NCT01429350). THERAPY is a prospective, multicentre, randomized, concurrent controlled study. Patients from 18 to 85 years old $(n=582)$ presenting with acute ischemic stroke symptoms, an NIHSS score of at least 8 or aphasic, and eligible for intravenous rtPA with evidence of a clot at least $8 \mathrm{~mm}$ long in the anterior circulation from reconstructed thin-sliced non-enhanced CT are randomly assigned 1:1 to intravenous rtPA therapy alone or combined intravenous rtPA therapy and adjunctive treatment with the Penumbra System. The primary endpoints are good 90-day functional outcome and incidence of serious adverse events. Secondary endpoints include good neurological and functional outcomes at discharge and 30 days, as well as the incidence of ICH.

\section{CONCLUSION}

Currently, intravenous rt-PA is the only approved treatment for acute ischemic stroke within $4.5 \mathrm{~h}$ from symptoms onset. However, many patients are still left undertreated, mainly due to the short time window and other contraindications for intravenous tPA. Several strategies have been developed to increase the number of treated patients. In the field of acute diagnosis, the use of multimodal neuroimaging allows physicians to evaluate not only the ischemic core but also the vessel pattern and collateral status. Concerning treatment, several molecules are being tested in randomized clinical trials with extended time windows. In this context, endovascular treatment is a promising technique that allows physicians not only to treat patients in extended time windows but also to treat patients in whom intravenous tPA has failed. Regarding endovascular treatments, a new era has emerged with new devices called stent-retrievers that have demonstrated higher rates of recanalization and clear superiority over previous devices employed in RCTs. However, the failure of recent endovascular trials to demonstrate the benefit of an endovascular approach over intravenous tPA has forced new trial designs. Several ongoing randomized clinical trials are now investigating two main research questions: the first one is whether bridging therapy is more effective than intravenous treatment alone and the second one is whether mechanical thrombectomy is more effective than the best medical treatment in patients ineligible for intravenous thrombolysis. We would therefore argue that the most advisable strategy to make progress in the field of reperfusion therapies for acute ischemic stroke is to randomize patients in well-designed clinical trials.

\section{ACKNOWLEDGMENTS}

This study was supported by grant PI11/00191 from the Instituto de Salud Carlos III and by grant RETICS INVICTUS RD12/0014/0008 from the Instituto de Salud Carlos III that was cofinanced by FEDER funds.

\section{REFERENCES}

1. The National Institute of Neurological Disorders and Stroke rt-PA Stroke Study Group. Tissue plasminogen activator for acute ischemic stroke. N Engl J Med (1995) 333:1581-7.

2. Hacke W, Kaste M, Bluhmki E, Brozman M, Dávalos A, Guidetti D, et al. Thrombolysis with alteplase 3 to 4.5 hours after acute ischemic stroke. $N$ Engl J Med (2008) 359:1317-29. doi:10.1056/NEJMoa0804656

3. Lansberg MG, Bluhmki E, Thijs VN. Efficacy and safety of tissue plasminogen activator 3 to 4.5 hours after acute ischemic stroke: a metaanalysis. Stroke (2009) 40:2438-41. doi:10.1161/STROKEAHA.109.552547

4. Hacke W, Donnan G, Fieschi C, Kaste M, von Kummer R, Broderick JP, et al. Association of outcome with early stroke treatment: pooled analysis of ATLANTIS, ECASS, and NINDS rt-PA stroke trials. Lancet (2004) 363:768-74. doi:10.1016/S0140-6736(04)15692-4

5. Wardlaw JM, Murray V, Berge E, Zoppo G, Sandercock P, Lindley RL, et al. Recombinant tissue plasminogen activator for acute ischaemic stroke?: an updated systematic review and meta-analysis. Lancet (2012) 379:2364-72. doi:10.1016/S0140-6736(12)60738-7

6. Toni D, Lorenzano S, Puca E, Prencipe M. The SITS-MOST registry. Neurol Sci (2006) 27(Suppl 3):S260-2. doi:10.1007/s10072-006-0632-9

7. Wahlgren N, Ahmed N, Dávalos A, Ford GA, Grond M, Hacke W, et al. Thrombolysis with alteplase for acute ischaemic stroke in the safe implementation of thrombolysis in stroke-monitoring study (SITS-MOST): an observational study. Lancet (2007) 369:275-82. doi:10.1016/s0140-6736(07)60149-4

8. Davis SM, Donnan GA, Parsons MW, Levi C, Butcher KS, Peeters A, et al. Effects of alteplase beyond $3 \mathrm{~h}$ after stroke in the echoplanar imaging thrombolytic evaluation trial (EPITHET): a placebo-controlled randomised trial. Lancet Neurol (2008) 7:299-309. doi:10.1016/S1474-4422(08)70044-9

9. Albers GW, Thijs VN, Wechsler L, Kemp S, Schlaug G, Skalabrin E, et al. Magnetic resonance imaging profiles predict clinical response to early reperfusion: the diffusion and perfusion imaging evaluation for understanding stroke evolution (DEFUSE) study. Ann Neurol (2006) 60:508-17. doi:10.1002/ana. 20976

10. Parsons MW, Miteff F, Bateman GA, Spratt N, Loiselle A, Attia J, et al. Acute ischemic stroke: imaging-guided tenecteplase treatment in an extended time window. Neurology (2009) 72:915-21. doi:10.1212/01.wnl.0000344168. 05315.9d

11. Parsons M, Spratt N, Bivard A, Campbell B, Chung K, Miteff F, et al. A randomized trial of tenecteplase versus alteplase for acute ischemic stroke. $N$ Engl J Med (2012) 366:1099-107. doi:10.1056/NEJMoa1109842

12. Hacke W, Albers G, Al-Rawi Y, Bogousslavsky J, Davalos A, Eliasziw M, et al. The desmoteplase in acute ischemic stroke trial (DIAS): a phase II MRI-based 9-hour window acute stroke thrombolysis trial with intravenous desmoteplase. Stroke (2005) 36:66-73. doi:10.1161/01.STR.0000149938.08731.2c

13. Furlan AJ, Eyding D, Albers GW, Al-Rawi Y, Lees KR, Rowley HA, et al. Dose escalation of desmoteplase for acute ischemic stroke (DEDAS): evidence of safety and efficacy 3 to 9 hours after stroke onset. Stroke (2006) 37:1227-31. doi:10.1161/01.STR.0000217403.66996.6d

14. Hacke W, Furlan AJ, Al-Rawi Y, Davalos A, Fiebach JB, Gruber F, et al. Intravenous desmoteplase in patients with acute ischaemic stroke selected by MRI perfusion-diffusion weighted imaging or perfusion CT (DIAS-2): a prospective, randomised, double-blind, placebo-controlled study. Lancet Neurol (2009) 8:141-50. doi:10.1016/S1474-4422(08)70267-9

15. Warach S, Al-rawi Y, Furlan AJ, Fiebach JB, Wintermark M, Lindstén A, et al. Refinement of the magnetic resonance diffusion-perfusion mismatch concept for thrombolytic patient selection insights from the desmoteplase in acute stroke trials. Stroke (2012) 43:2313-8. doi:10.1161/STROKEAHA.111.642348

16. Von Kummer R, Albers GW, Mori E. The desmoteplase in acute ischemic stroke (DIAS) clinical trial program. Int J Stroke (2012) 7:589-96. doi:10.1111/j.17474949.2012.00910.x

17. De Silva DA, Churilov L, Olivot J-M, Christensen S, Lansberg MG, Mlynash M, et al. Greater effect of stroke thrombolysis in the presence of arterial obstruction. Ann Neurol (2011) 70:601-5. doi:10.1002/ana.22444

18. Saqqur M, Uchino K, Demchuk AM, Molina CA, Garami Z, Calleja S, et al. Site of arterial occlusion identified by transcranial doppler predicts the response to intravenous thrombolysis for stroke. Stroke (2007) 38:948-54. doi:10.1161/01. STR.0000257304.21967.ba

19. Barreto AD, Alexandrow AV, Shen L, Sisson A, Bursaw AW, Shahota P, et al. CLOTBUST-hands free. Pilot safety study of a novel operator-independent 
ultrasound device in patients with acute ischemic stroke. Stroke (2013) 44:3376-81. doi:10.1161/STROKEAHA.113.002713

20. Furlan A, Higashida R, Wechsler L, Gent M, Rowley H, Kase C, et al. Intra-arterial prourokinase for acute ischemic stroke. The PROACT II study: a randomized controlled trial. JAMA (1999) 282:2003-11.

21. Study Investigators IMS. Combined intravenous and intra-arterial recanalization for acute ischemic stroke: the interventional management of stroke study. Stroke (2004) 35:904-11. doi:10.1161/01.STR.0000121641.77121.98

22. Tomsick T, Broderick J, Carrozella J, Khatri P, Hill M, Palesch Y, et al. Revascularization results in the interventional management of stroke II trial. AJNR Am J Neuroradiol (2008) 29:582-7. doi:10.3174/ajnr.A0843

23. The IMS study investigators. The interventional management of stroke (IMS) II study. Stroke (2007) 38:2127-35. doi:10.1161/STROKEAHA.107.483131

24. Smith WS, Sung G, Starkman S, Saver JL, Kidwell CS, Gobin YP, et al. Safety and efficacy of mechanical embolectomy in acute ischemic stroke: results of the MERCI trial. Stroke (2005) 36:1432-8. doi:10.1161/01.STR.0000171066. 25248.1d

25. Smith WS, Sung G, Saver J, Budzik R, Duckwiler G, Liebeskind DS, et al. Mechanical thrombectomy for acute ischemic stroke: final results of the multi MERCI trial. Stroke (2008) 39:1205-12. doi:10.1161/STROKEAHA.107. 497115

26. Penumbral Pivotal Stroke Trial Investigators. The penumbra pivotal stroke trial: safety and effectiveness of a new generation of mechanical devices for clot removal in intracranial large vessel occlusive disease. Stroke (2009) 40:2761-8. doi:10.1161/STROKEAHA.108.544957

27. Kim D, Jahan R, Starkman S, Abolian A, Kidwell CS, Vinuela F, et al. Endovascular mechanical clot retrieval in a broad ischemic stroke cohort. AJNR Am J Neuroradiol (2006) 27:2048-52.

28. Lansberg MG, Straka M, Kemp S, Mlynash M, Wechsler LR, Jovin TG, et al. MRI profile and response to endovascular reperfusion after stroke (DEFUSE 2): a prospective cohort study. Lancet Neurol (2012) 11:860-7. doi:10.1016/S14744422(12)70203-X

29. Rha J-H, Saver JL. The impact of recanalization on ischemic stroke outcome: a meta-analysis. Stroke (2007) 38:967-73. doi:10.1161/01.STR.0000258112. 14918.24

30. Molina CA. Futile recanalization in mechanical embolectomy trials: a call to improve selection of patients for revascularization. Stroke (2010) 41:842-3. doi:10.1161/STROKEAHA.110.580266

31. Hussein HM, Georgiadis AL, Vazquez G, Miley JT, Memon MZ, Mohammad $\mathrm{YM}$, et al. Occurrence and predictors of futile recanalization following endovascular treatment among patients with acute ischemic stroke: a multicenter study. AJNR Am J Neuroradiol (2010) 31:454-8. doi:10.3174/ajnr.A2006

32. Chimowitz MI, Lynn MJ, Derdeyn CP, Turan TN, Fiorella D, Lane BF, et al. Stenting versus aggressive medical therapy for intracranial arterial stenosis. $N$ Engl J Med (2011) 365:993-1003. doi:10.1056/NEJMoa1105335

33. Sauvageau E, Levy EI. Self-expanding stent-assisted middle cerebral artery recanalization: technical note. Neuroradiology (2006) 48:405-8. doi:10.1007/ s00234-006-0077-0

34. Levy EI, Mehta R, Gupta R, Hanel RA, Chamczuk AJ, Fiorella D, et al. Selfexpanding stents for recanalization of acute cerebrovascular occlusions. AJNR Am J Neuroradiol (2007) 28:816-22.

35. Kim SM, Lee DH, Kwon SU, Choi CG, Kim SJ, Suh DC. Treatment of acute ischemic stroke: feasibility of primary or secondary use of a self-expanding stent (Neuroform) during local intra-arterial thrombolysis. Neuroradiology (2012) 54:35-41. doi:10.1007/s00234-010-0813-3

36. Castaño C, Serena J, Dávalos A. Use of the new solitaire (TM) AB device for mechanical thrombectomy when merci clot retriever has failed to remove the clot. A case report. Interv Neuroradiol (2009) 15:209-14.

37. Castaño C, Dorado L, Guerrero C, Millán M, Gomis M, Perez de la Ossa N, et al. Mechanical thrombectomy with the solitaire $\mathrm{AB}$ device in large artery occlusions of the anterior circulation: a pilot study. Stroke (2010) 41:1836-40. doi:10.1161/STROKEAHA.110.584904

38. Cohen JE, Gomori JM, Leker RR, Eichel R, Arkadir D, Itshayek E. Preliminary experience with the use of self-expanding stent as a thrombectomy device in ischemic stroke. Neurol Res (2011) 33:214-9. doi:10.1179/1743132810Y. 0000000015

39. Cohen JE, Gomori JM, Leker RR, Moscovici S, Ramirez-deNoriega F, Itshayek E. Recanalization with stent-based mechanical thrombectomy in anterior circulation major ischemic stroke. J Clin Neurosci (2012) 19:39-43. doi:10.1016/ j.jocn.2011.06.015

40. Machi P, Costalat V, Lobotesis K, Lima Maldonado I, Vendrell JF, Riquelme $\mathrm{C}$, et al. Solitaire FR thrombectomy system: immediate results in 56 consecutive acute ischemic stroke patients. J NeuroInterv Surg (2012) 4:62-6. doi:10.1136/jnis.2010.004051

41. Mendonça N, Flores A, Pagola J, Rubiera M, Rodríguez-Luna D, De Miquel MA, et al. Trevo system: single-center experience with a novel mechanical thrombectomy device. J Neuroimaging (2013) 23:7-11. doi:10.1111/j.15526569.2011.00666.x

42. Möhlenbruch M, Seifert M, Okulla T, Wüllner U, Hadizadeh DR, Nelles M, et al. Mechanical thrombectomy compared to local-intraarterial thrombolysis in carotid T and middle cerebral artery occlusions. Clin Neuroradiol (2012) 22:141-7. doi:10.1007/s00062-011-0099-9

43. Pérez MA, Miloslavski E, Fischer S, Bäzner H, Henkes H. Intracranial thrombectomy using the solitaire stent: a historical vignette. J Neurointerv Surg (2012) 4:e32. doi:10.1136/neurintsurg-2011-010149

44. Rohde S, Haehnel S, Herweh C, Pham M, Stampfl S, Ringleb PA, et al. Mechanical thrombectomy in acute embolic stroke: preliminary results with the revive device. Stroke (2011) 42:2954-6. doi:10.1161/STROKEAHA.111.616763

45. Roth C, Papanagiotou P, Behnke S, Walter S, Haass A, Becker C, et al. Stent-assisted mechanical recanalization for treatment of acute intracerebral artery occlusions. Stroke (2010) 41:2559-67. doi:10.1161/STROKEAHA.110. 592071

46. Stampfl S, Hartmann M, Ringleb PA, Haehnel S, Bendszus M, Rohde S. Stent placement for flow restoration in acute ischemic stroke: a single-center experience with the solitaire stent system. AJNR Am J Neuroradiol (2011) 32:1245-8. doi:10.3174/ajnr.A2505

47. Venker C, Stracke P, Berlit P, Diehl RR, Kurre W, Sorgenfrei U, et al. New options in the therapeutic management of acute ischaemic stroke. Good results with combined i. v. and i.a. lysis and mechanical thrombectomy. Fortschr Neurol Psychiatr (2010) 78:652-7. doi:10.1055/s-0029-1245582

48. Wehrschuetz M, Wehrschuetz E, Augustin M, Niederkorn K, Deutschmann $\mathrm{H}$, Ebner F. Early single center experience with the solitaire thrombectomy device for the treatment of acute ischemic stroke. Interv Neuroradiol (2011) 17: 235-40.

49. Castro-Afonso L, Abud T, Pontes-Neto O, Monsignore L, Nakiri G, CougoPinto P, et al. Mechanical thrombectomy with solitaire stent retrieval for acute ischemic stroke in a Brazilian population. Clinics (2012) 17:1379-86.

50. Miteff F, Faulder KC, Goh AC, Steinfort BS, Sue C, Harrington TJ. Mechanical thrombectomy with a self-expanding retrievable intracranial stent (solitaire $\mathrm{AB})$ : experience in 26 patients with acute cerebral artery occlusion. AJNR Am J Neuroradiol (2011) 32:1078-81. doi:10.3174/ajnr.A2447

51. San Román L, Obach V, Blasco J, Macho J, Lopez A, Urra X, et al. Singlecenter experience of cerebral artery thrombectomy using the TREVO device in 60 patients with acute ischemic stroke. Stroke (2012) 43:1657-9. doi:10.1161/ STROKEAHA.111.640011

52. Menon BK, Kochar P, Ah-Seng A, Almekhlafi MA, Modi J, Wong JH, et al. Initial experience with a self-expanding retrievable stent for recanalization of large vessel occlusions in acute ischemic stroke. Neuroradiology (2012) 54:147-54. doi:10.1007/s00234-010-0835-x

53. Park H, Hwang GJ, Jin S-C, Jung C-K, Bang JS, Han MK, et al. A retrieval thrombectomy technique with the solitaire stent in a large cerebral artery occlusion. Acta Neurochir (2011) 153:1625-31. doi:10.1007/s00701-0110999-0

54. Costalat V, Machi P, Lobotesis K, Maldonado I, Vendrell JF, Riquelme C, et al. Rescue, combined, and stand-alone thrombectomy in the management of large vessel occlusion stroke using the solitaire device: a prospective 50-patient single-center study: timing, safety, and efficacy. Stroke (2011) 42:1929-35. doi:10.1161/STROKEAHA.110.608976

55. Suh SH, Lee K-Y, Hong CK, Kim BM, Kim C-H, Chung T-S, et al. Temporary stenting and retrieval of the self-expandable, intracranial stent in acute middle cerebral artery occlusion. Neuroradiology (2009) 51:541-4. doi:10.1007/s00234009-0530-y

56. Dávalos A, Pereira VM, Chapot R, Bonafé A, Andersson T, Gralla J. Retrospective multicenter study of solitaire FR for revascularization in the treatment of acute ischemic stroke. Stroke (2012) 43:2699-705. doi:10.1161/STROKEAHA. 112.663328 
57. Mpotsaris A, Bussmeyer M, Loehr C, Oelerich M, Bucher H, Weber W. Mechanical thrombectomy in severe acute stroke:preliminary results of the soliatire stent. J Neurol Neurosurg Psychiatry (2012) 83:117-8. doi:10.1136/jnnp.2010. 225573

58. Pereira VM, Gralla J, Davalos A, Bonafe A, Castano C, Chapot R, et al. Prospective, multicenter, single-arm study of mechanical thrombectomy using solitaire flow restoration in acute ischemic stroke. Stroke (2013) 44:2802-7. doi:10.1161/STROKEAHA.113.001232

59. Jansen O, Macho JM, Killer-Oberpfalzer M, Liebeskind D, Wahlgren N. Neurothrombectomy for the treatment of acute ischemic stroke: results from the TREVO study. Cerebrovasc Dis (2013) 36:218-25. doi:10.1159/000353990

60. Saver JL, Jahan R, Levy EI, Jovin TG, Baxter B, Nogueira RG, et al. Solitaire flow restoration device versus the Merci Retriever in patients with acute ischaemic stroke (SWIFT): a randomised, parallel-group, non-inferiority trial. Lancet (2012) 380:1241-9. doi:10.1016/S0140-6736(12)61384- 1

61. Nogueira RG, Lutsep HL, Gupta R, Jovin TG, Albers GW, Walker GA, et al. Trevo versus Merci retrievers for thrombectomy revascularisation of large vessel occlusions in acute ischaemic stroke (TREVO 2): a randomised trial. Lancet (2012) 380:1231-40. doi:10.1016/S0140-6736(12)61299-9

62. Mendonça N, Flores A, Pagola J, Rubiera M, Rodríguez-Luna D, De Miquel MA, et al. Trevo versus solitaire a head-to-head comparison between two heavy weights of clot retrieval. J Neuroimaging (2012) 5:1-4. doi:10.1111/j.1552-6569. 2012.00730.x

63. Broderick JP, Palesch YY, Demchuk AM, Yeatts SD, Khatri P, Hill MD, et al Endovascular therapy after intravenous t-PA versus t-PA alone for stroke. $N$ Engl J Med (2013) 368:893-903. doi:10.1056/NEJMoa1214300

64. Ciccone A, Valvassori L, Nichelatti M, Sgoifo A, Ponzio M, Sterzi R, et al. Endovascular treatment for acute ischemic stroke. N Engl J Med (2013) 368:904-13. doi:10.1056/NEJMoa1213701

65. Kidwell CS, Jahan R, Gornbein J, Alger JR, Nenov V, Ajani Z, et al. A trial of imaging selection and endovascular treatment for ischemic stroke. $\mathrm{NEngl} \mathrm{J} \mathrm{Med}$ (2013) 368:914-23. doi:10.1056/NEJMoa1212793

66. Shuaib A, Butcher K, Mohammad AA, Saqqur M, Liebeskind DS. Collateral blood vessels in acute ischaemic stroke: a potential therapeutic target. Lancet Neurol (2011) 10:909-21. doi:10.1016/S1474-4422(11)70195-8

67. Nogueira RG, Gupta R, Dávalos A. IMS-III and synthesis expansion trials of endovascular therapy in acute ischemic stroke: how can we improve? Stroke (2013) 44:3272-4. doi:10.1161/STROKEAHA.113.002380

68. Qureshi AI, Abd-Allah F, Aleu A, Connors JJ, Hanel RA, Hassan AE, et al. Endovascular treatment for acute ischemic stroke patients: implications and interpretation of IMS III, MR RESCUE, and synthesis expansion trials: a report from the working group of international congress of interventional neurology. J Vasc Interv Neurol (2014) 7:56-75.

69. Mokin M, Khalessi AA, Mocco J, Lanzino G, Dumont TM, Hanel RA, et al. Endovascular treatment of acute ischemic stroke: the end or just the beginning? Neurosurg Focus (2014) 36:E5. doi:10.3171/2013.10.FOCUS13374

70. TIMI Study Group. The thrombolysis in myocardial infarction (TIMI) trial. Phase I findings. N Engl J Med (1985) 312:932-6.

71. Higashida RT, Furlan AJ, Roberts H, Tomsick T, Connors B, Barr J, et al. Technology assessment committee of the american society of interventional and therapeutic neuroradiology; technology assessment committee of the society of interventional radiology. trial design and reporting standards for intra-arterial cerebral thrombolysis for acute ischemic stroke. Stroke (2003) 34:e109-37. doi:10.1161/01.STR.0000082721.62796.09

72. Yoo AJ, Simonsen CZ, Prabhakaran S, Chaudhry ZA, Issa M, Fugate JE, et al. Refining angiographic biomarkers of reperfusion: modified TICI is superior to TIMI for predicting clinical outcomesafter intra-arterial therapy. Stroke (2013) 44:A62. doi:10.1161/STROKEAHA.113.001990

73. Zaidat O, Yoo AJ, Khatri P, Tomsik TA, von Kummer R, Saver JL, et al. for the cerebral angiographic revascularization grading (CARG) collaborators, STIR revascularization working group, and STIR thrombolysis in cerebral infarction (TICI) task force. Recommendations on angiographic revascularization grading standards for acute ischemic stroke. A consensus statement. Stroke (2013) 44:2650-63. doi:10.1161/STROKEAHA.113.001972

74. Sun C-HJ, Ribo M, Goyal M, Yoo AJ, Jovin T, Cronin CA, et al. Door-to-puncture: a practical metric for capturing and enhancing system processes associated with endovascular stroke care, preliminary results from the rapid reperfusion registry. J Am Heart Assoc (2014) 3:e000859. doi:10.1161/JAHA.114.000859

75. John N, Mitchell P, Dowling R, Yan B. Is general anaesthesia preferable to conscious sedation in the treatment of acute ischaemic stroke with intra-arterial mechanical thrombectomy? A review of the literature. Neuroradiology (2013) 55:93-100. doi:10.1007/s00234-012-1084-y

76. Liebeskind DS. Collateral lessons from recent acute ischemic stroke trials. Neurol Res (2014) 36:397-402. doi:10.1179/1743132814Y.0000000348

77. Liebeskind DS, Tomsick TA, Foster LD, Yeatts SD, Carrozzella J, Demchuk AM, et al. Collaterals at angiography and outcomes in the interventional management of stroke (IMS) III trial. Stroke (2014) 45:759-64. doi:10.1161/STROKEAHA. 113.004072

78. Lima FO, Furie KL, Silva GS, Lev MH, Camargo ECS, Singhal AB, et al. Prognosis of untreated strokes due to anterior circulation proximal intracranial arterial occlusions detected by use of computed tomography angiography. JAMA Neurol (2014) 71:151-7. doi:10.1001/jamaneurol.2013.5007

79. Demchuk AM, Menon B, Goyal M. Imaging-based selection in acute ischemic stroke trials - a quest for imaging sweet spots. Ann N Y Acad Sci (2012) 1268:63-71. doi:10.1111/j.1749-6632.2012.06732.x

80. Shuaib A, Bornstein NM, Diener HC, Dillon HC, Fisher M, Hammer MD, et al. Partial aortic occlusion for cerebral perfusion augmentation: safety and efficacy of NeuroFlo in acute ischemic stroke trial. Stroke (2011) 42:1680-90. doi:10.1161/STROKEAHA.110.609933

81. Leker RR, Molina C, Cockroft K, Liebeskind DS, Concha M, Shuaib A, et al. Effects of age on outcome in the SENTIS trial: better outcomes in elderly patients. Cerebrovasc Dis (2012) 34:263-71. doi:10.1159/000342668

82. Abilleira S, Cardona P, Ribó M, Millán M, Obach V, Roquer J, et al. Outcomes of a contemporary cohort of 536 consecutive endovascular therapy. Stroke (2014) 45:1046-52. doi:10.1161/STROKEAHA.113.003489

83. Hong KS, Saver JL. Years of disability-adjusted life gained as a result of thrombolytic therapy for acute ischemic stroke. Stroke (2010) 41:471-7. doi:10.1161/ STROKEAHA.109.571083

84. Demchuk AM, Goyal M, Yeatts SD, Carrozzella J, Foster LD, et al. For the IMS III investigators. recanalization and clinical outcome of occlusion sites at baseline CT angiography in the interventional management of stroke III Trial. Radiology (2014) 5:132649.

85. Heiss WD, Huber M, Fink GR, Herholz K, Pietrzyk U, Wagner R, et al. Progressive derangement of periinfarct viable tissue in ischemic stroke. J Cereb Blood Flow Metab (1992) 12:193-203.

86. Natarajan SK, Snyder KV, Siddiqui AH, Ionita CC, Hopkins LN, Levy EI. Safety and effectiveness of endovascular therapy after 8 hours of acute ischemic stroke onset and wake-up strokes. Stroke (2009) 40:3269-74. doi:10.1161/ STROKEAHA.109.555102

87. Linfante I, Reddy AS, Andreone V, Caplan LR, Selim M, Hirsch JA. Intra-arterial thrombolysis in patients treated with warfarin. Cerebrovasc Dis (2005) 19:133-5. doi:10.1159/000083181

88. Chalela JA, Katzan I, Liebeskind DS, Rasmussen P, Zaidat O, Suarez JI, et al. Safety of intra-arterial thrombolysis in the postoperative period. Stroke (2001) 32:1365-9. doi:10.1161/01.STR.32.6.1365

Conflict of Interest Statement: The authors declare that the research was conducted in the absence of any commercial or financial relationships that could be construed as a potential conflict of interest.

Received: 07 July 2014; accepted: 18 October 2014; published online: 19 November 2014.

Citation: Gomis M and Dávalos A (2014) Recanalization and reperfusion therapies of acute ischemic stroke: what have we learned, what are the major research questions, and where are we headed? Front. Neurol. 5:226. doi: 10.3389/fneur.2014.00226 This article was submitted to Stroke, a section of the journal Frontiers in Neurology. Copyright $(2014$ Gomis and Dávalos. This is an open-access article distributed under the terms of the Creative Commons Attribution License (CC BY). The use, distribution or reproduction in other forums is permitted, provided the original author (s) or licensor are credited and that the original publication in this journal is cited, in accordance with accepted academic practice. No use, distribution or reproduction is permitted which does not comply with these terms. 